\title{
Decrease in sensitisation rate and intestinal anaphylactic response after nitric oxide synthase inhibition in a food hypersensitivity model
}

\author{
M J Fargeas, V Theodorou, B Weirich, J Fioramonti, L Buéno
}

\begin{abstract}
Background-Although nitric oxide (NO) has been found to have a role in gut inflammation and to modulate immunoglobulin production, little is known about its part in food hypersensitivities.

Aim-This study aimed to evaluate the role of NO through the inhibition of constitutive and inducible NO synthase (cNOS and iNOS respectively) on the sensitisation process (antibody titres) and on intestinal anaphylactic responses (colonic hypersecretion upon antigen challenge). Animals and methods-Guinea pigs sensitised to cow's milk proteins were treated either during the sensitisation period or before antigen challenge by $\mathrm{N}$-nitro-Larginine methyl ester (L-NAME) (inhibiting both cNOS and iNOS) or amino-guanidine (selective iNOS inhibitor).
\end{abstract}

Results-Chronic treatment by L-NAME or aminoguanidine reduced antibody titres and the secretory response to antigen challenge. In contrast, only L-NAME administered before challenge was able to antagonise the hypersecretion induced by the challenge.

Conclusions-NO generated by iNOS has a role in the sensitisation process: iNOS inhibition results in lower rates of antibodies leading to a reduced secretory response upon challenge. In contrast, blockade of colonic hypersecretion by L-NAME but not by aminoguanidine suggests that NO via cNOS is a key mediator in intestinal anaphylactic reactions. (Gut 1996; 38: 598-602)

Keywords: nitric oxide, sensitisation rate, intestinal hypersecretion.

\footnotetext{
Department of

Pharmacology-

Toxicology, Institut

National de la

Recherche

Agronomique,

Toulouse, France

M J Fargeas

$\mathrm{V}$ Theodorou

B Weirich

J Fioramonti

L Buéno

Correspondence to:

Correspondence to:
Dr M J Fargeas, Department

of Pharmacology-

Toxicology, INRA, 180

BP3 31931 Toulouse Cedex,

BP3 31931

Accepted for publication

23 October 1995
}

The production of nitric oxide (NO) has been shown in a great number of mammalian cells as diverse as endothelial cells, ${ }^{1}$ neurons, ${ }^{2}$ intestinal mucosal, ${ }^{3}$ and immune cells. ${ }^{4}$ This short lived molecule is produced from L-arginine by an enzyme, NO synthase. Two distinct types of NO synthase have been described, a constitutive $\mathrm{Ca}^{2+}$ /calmodulin dependent enzyme (cNOS) and an inducible form (iNOS), $\mathrm{Ca}^{2+} /$ calmodulin independent induced by cytokines or endotoxins. ${ }^{2}$ While cNOS is found in endothelial vascular cells, neurons, and intestinal cells, iNOS has been identified in a variety of immunocompetent cells including macrophages $^{5}$ and neutrophils. ${ }^{6}$
The role of NO in gut inflammation is evident but controversial: NO being either protective or deleterious depending on the nature of the insult, its duration (acute or chronic inflammation), and the enzymatic source of NO (cNOS or iNOS). ${ }^{7}$ Although there is increasing interest in the role of NO in gut inflammation, very few studies consider the part played by NO in food allergies. Nevertheless, these pathologies imply inflammatory mediator production and release involving NO generation.

This study was designed to evaluate the role of NO in the sensitisation process through chronic inhibition of cNOS and iNOS during the period of sensitisation in a model of cow's milk allergy in the guinea pig. ${ }^{8}$ Because NO synthase inhibition has been reported to increase intestinal permeability, ${ }^{9}$ which is an important factor for antigen uptake, this parameter was assessed during the sensitisation period. In addition, the role of NO in the anaphylactic response (intestinal hypersecretion) induced by antigen challenge in sensitised animals was also investigated.

\section{Methods}

ANIMALS - SENSITISATION

Thirty six male Dunkin-Hartley guinea pigs (250-300 g) divided into six groups were used for these experiments (Interfauna, Loches, France). A milk protein-free solid pellet diet was supplied to all animals. Animals were sensitised to cow's milk proteins by giving them only fresh pasteurised cow's milk to drink instead of water for four weeks. ${ }^{8}$ These animals were allowed to drink water five to six days before the day of antigen challenge. A group of six animals had water available instead of milk and was used as control.

\section{ANTIBODY TITRES}

Blood was drawn by cardiac puncture the day before antigen challenge to determine anti- $\beta$ lactoglobulin antibody titres by passive cutaneous anaphylaxis (PCA) test. Briefly, $100 \mu l$ of the diluted sera ranging from $1: 2$ to $1: 256$ were injected intradermally into the shaved flanks of naive guinea pigs. Two days later, $2 \cdot 5$ $\mathrm{mg}$ of $\beta$ lactoglobulin in Evans' blue dye (1\% in $9 \% \mathrm{NaCl}$ solution) were injected intravenously in a final volume of $0.5 \mathrm{ml}$. One hour later, PCA reactivity was measured as the highest dilution which yielded a positive response (local skin blueing with a diameter $\geqslant 4 \mathrm{~mm}$ ). 
Titres were expressed as the log of the highest dilution giving blue patches.

\section{EVALUATION OF ANTIGEN INDUCED COLONIC SECRETION}

Modification of water intestinal transport is a characteristic feature of intestinal anaphylaxis. ${ }^{10}$ To assess the response to antigen challenge, we measured the net water flux of an isolated colonic loop. ${ }^{11} 12 \mathrm{~A}$ midline laparotomy was performed in anaesthetised (urethane $2 \mathrm{~g} / \mathrm{kg}$ intraperitoneally (ip)) guinea pigs to expose the large intestine. A $5 \mathrm{~cm}$ segment of proximal colon $3 \mathrm{~cm}$ from the caecocolonic junction was isolated and cannulated for intraluminal perfusion. After cleansing the contents, the loop was replaced in the abdominal cavity, which was then closed, and the colonic segment was infused with a Ringer's buffer solution containing $1 \mu \mathrm{Ci} / 1$ of $\left({ }^{14} \mathrm{C}\right)$ polyethylene glycol 4000 as a marker and $5 \mathrm{~g} / \mathrm{l}$ of cold polyethylene glycol 4000 as a carrier. The loop was infused at a constant rate $(6 \mathrm{ml} / \mathrm{h})$ and the effluent was collected for 15 minute periods over 180 minutes. After an equilibration period (90 minutes), antigen challenge was performed by adding $\beta$ lactoglobulin $(100 \mathrm{mg}$ ) to the Ringer's solution. Antigen was infused for 30 minutes. ${ }^{14} \mathrm{C}$ activity in collected samples was measured by liquid scintillation, and water flux for every 15 minute period was calculated using the following formula:

Net water flux $(\mu 1 / \mathrm{cm} / \mathrm{h})=(1-$ dpms $/$ dpmx $) \times P / L$

where dpms and dpmx are the ${ }^{14} \mathrm{C}$ activities in Ringer's solution and the effluent respectively; $P$ is the perfusion rate $(\mu 1 / \mathrm{h})$ and $L$ the length $(\mathrm{cm})$ of the colonic segment.

Water flux values measured over two consecutive 15 minute periods were averaged to obtain a mean net flux of water over a 30 minute period. Positive values represented net absorption of water and negative values, net secretion.

\section{INTESTINAL PERMEABILITY}

Intestinal permeability was determined in control animals (water) and milk-drinking guinea pigs chronically treated or not with NO synthase inhibitors. This evaluation was performed before milk diet and later on, every week during the four weeks of sensitisation.

To assess epithelial permeability $1 \mathrm{ml}$ of the probe $\left({ }^{51} \mathrm{Cr}-\mathrm{EDTA}, 3 \mu \mathrm{Ci} /\right.$ guinea pig) was delivered by gastric intubation. Each animal was placed for 24 hours in a metabolic cage permitting us to collect separately urine and faeces. The radioactivity of urine $(1 \mathrm{ml})$ was counted in a gamma counter (Cobra II, Packard, Meriden, CT, USA). The percentage of recovery of ${ }^{51} \mathrm{Cr}$-EDTA for 24 hours was calculated from the administered dose.

NO SYNTHASE INHIBITION TREATMENT

NO synthase inhibition was achieved by using either N-nitro-L-arginine methyl ester (LNAME) which is a competitive inhibitor of both cNOS and iNOS, or aminoguanidine, a potent and selective antagonist of iNOS..$^{13} 14$ Two groups of six guinea pigs received daily administrations of either L-NAME $(10 \mathrm{mg} / \mathrm{kg}$ ip) or aminoguanidine (2 $\mathrm{mg} / \mathrm{kg}$ ip) for four weeks, six days a week, during the period of milk drinking (chronic treatment). Two other groups were given ip L-NAME $(10 \mathrm{mg} / \mathrm{kg})$ or aminoguanidine $(2 \mathrm{mg} / \mathrm{kg})$ one hour before infusion of antigen challenge (acute treatment). The doses used were chosen in accordance with the abundant published reports. Controls were given saline.

\section{STATISTICAL ANALYSIS}

Values were mean (SD) from six animals. They were compared using analysis of variance (ANOVA) and Student's $t$ test for unpaired data where appropriate.

\section{Results}

\section{EFFECT OF CHRONIC NO SYNTHASE INHIBITION}

\section{Sensitisation rate}

There was no positive response to the PCA test in control (non-sensitised) animals. In control sensitised animals, the IgE-IgG titres determined by the PCA test reached $1.80(0.36)$, ranging from $1 \cdot 5-2 \cdot 4$. In L-NAME treated rats, the titre was $1.02(0.65)$ ranging from $0.3-1.8$ and was significantly different $(p=0.027)$ from values in untreated animals. Similarly, aminoguanidine significantly $(p=0.013)$ decreased antibody titres: mean $0.90(0.63)$, range $0-1.5$ (Fig 1). The mean values corresponded to blue patches appearing at a mean serum dilution of 1:8 (treated animals) whereas in untreated ones the dilution was 1:64.

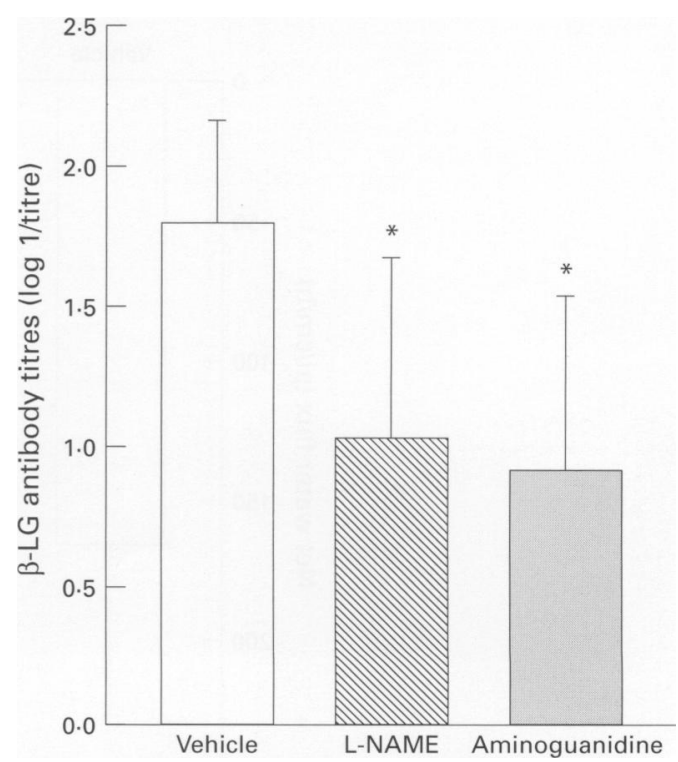

Figure 1: Antibodies to $\beta$ lactoglobulin ( $\beta-L G)$ evaluated by passive cutaneous anaphylaxis test in vehicle and NO synthase inhibitor treated guinea pigs. Antibody titres are significantly lower in animals treated by $N$-nitro-L-arginine methyl ester $(L-N A M E)(p=0.027)$ or aminoguanidine $(p=0.013)$ during the sensitising period, than in controls. ${ }^{\star}$ Significantly different from controls $(n=6)$. 


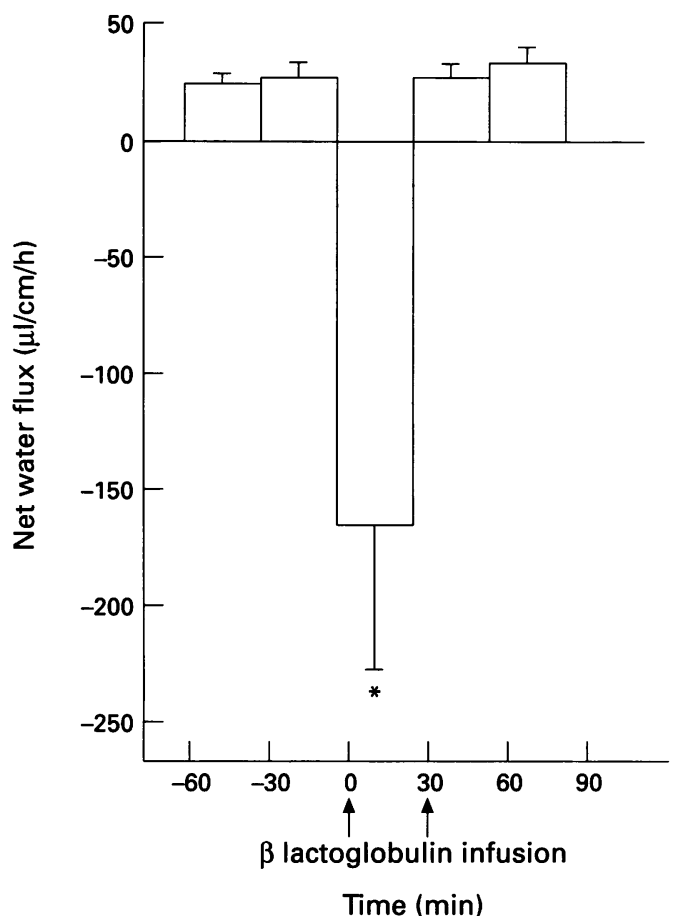

Figure 2: Effect of intracolonic infusion of $\beta$ lactoglobulin on colonic net water flux in cow's milk sensitised guinea pigs. Note that antigen challenge reverses the water flux from an absorption to a net secretion. ${ }^{\star}$ Significantly different from basal values $(p<0 \cdot 01 ; n=6)$.

\section{Challenge induced colonic hypersecretion}

Infusion of $\beta$ lactoglobulin (100 mg) in sensitised animals reversed the net water flux of the colonic loop from an absorptive to a secretory state. This change did not occur in non-sensitised animals: in these, water absorption was constant throughout the time course study. Basal net water flux in sensitised animals was $26 \cdot 2(4 \cdot 8) \mu \mathrm{l} / \mathrm{cm} / \mathrm{h}$ during the hour before challenge. Intracolonic perfusion of $\beta$ lactoglobulin over 30 minutes induced a net secretion of water reaching $-165.8(62.5) \mu 1 / \mathrm{cm} / \mathrm{h}$ (Fig 2).

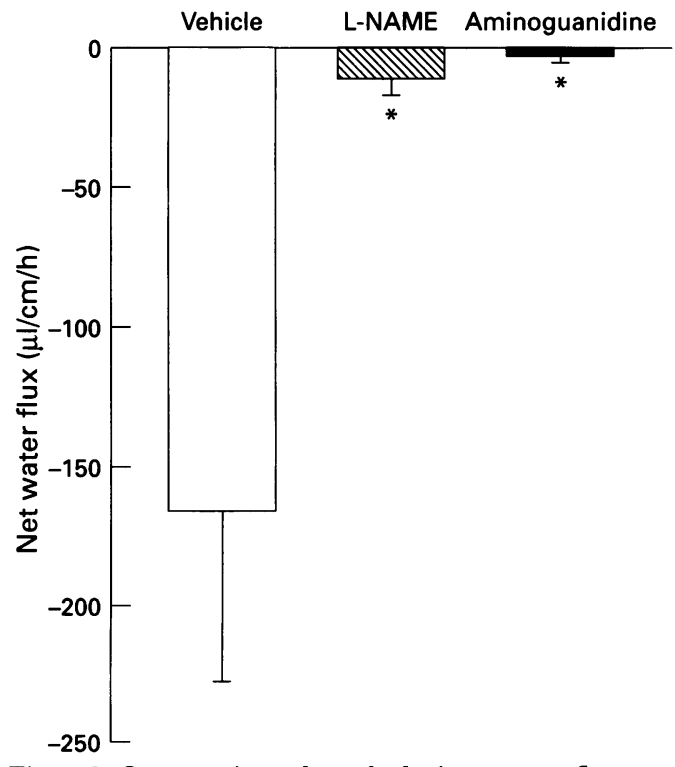

Figure 3: Comparative values of colonic net water flux during antigen challenge in vehicle and $N$-nitro-L-arginine methyl ester ( $L-N A M E)$ or aminoguanidine treated animals (chronic treatment during the sensitisation period). L-NAME and aminoguanidine significantly reduced the hypersecretion induced by $\beta$ lactoglobulin. ${ }^{\star}$ Significantly different from vehicle values $(p<0 \cdot 01 ; n=6)$.
After stopping $\beta$ lactoglobulin challenge, the net water absorption was restored and values after infusion were not significantly different from basal values.

In sensitised animals, treated chronically by L-NAME or aminoguanidine, the challenge induced hypersecretion was significantly $(\mathrm{p}<0.01)$ reduced: $-9.5(6.5)$ and $-1.4(3.3)$ respectively $v-165.8(62.5) \quad \mu \mathrm{l} / \mathrm{cm} / \mathrm{h}$ in untreated animals (Fig 3).

\section{Intestinal permeability}

Intestinal permeability in milk-drinking animals measured after one week of L-NAME or aminoguanidine treatment was significantly $(p<0.05)$ higher than that in vehicle treated animals. Thereafter, the intestinal permeability decreased progressively and at the end of the sensitisation period (four weeks) the mean values were equivalent in the three groups (vehicle, L-NAME, aminoguanidine) but significantly lower than the first week values for treated animals only (Fig 4).

\section{EFFECT OF ACUTE NO SYNTHASE INHIBITION} ON CHALLENGE INDUCED HYPERSECRETION Previous administration of L-NAME (10 $\mathrm{mg} / \mathrm{kg}$ ip, one hour before challenge) in sensitised animals antagonised the hypersecretion triggered by $\beta$ lactoglobulin challenge (net water flux +3.7 (8.9) $v-165.8 \quad(62.5)$ $\mu \mathrm{l} / \mathrm{cm} / \mathrm{h}$ ). In contrast, administration of aminoguanidine $(2 \mathrm{mg} / \mathrm{kg})$ under the same conditions could not prevent the secretory effects of $\beta$ lactoglobulin on the colonic loop (net water flux $-95 \cdot 7(35 \cdot 2) \mu \mathrm{l} / \mathrm{cm} / \mathrm{h}$ ). Neither L-NAME nor aminoguanidine changed the basal values when administered alone.

\section{Discussion}

Our results show that chronic treatment by NOS inhibitors and the consequent reduction in NO production during the sensitisation period reduces the antibody titres when compared with untreated animals. This finding was obtained in a model of food allergy which has already been used to compare the effect of oral $v$ parenteral sensitisation to cow's milk proteins on mucosal permeability. ${ }^{15} \mathrm{We}$ preferred to use the oral route for sensitisation rather than the systemic route because this resembles the sensitisation that occurs in infants with cow's milk allergy diseases and is therefore a more clinically relevant model. The reduction in anti- $\beta$ lactoglobulin antibody titres observed in our study is in agreement with results from in vitro studies that have shown a regulatory role of NO in the interleukin (IL) -4 induced IgE production by human peripheral blood mononuclear cells. ${ }^{16}$ In this work, a competitive inhibitor of L-arginine, $\mathrm{N}$-monomethyl Larginine (L-NMMA) was shown to suppress IgE production driven by IL- 4 by preventing NO synthesis. Indeed, IL-4 is known to be linked to allergic responses because it has a major role in IgE synthesis by B-lymphocytes. ${ }^{17}$ 


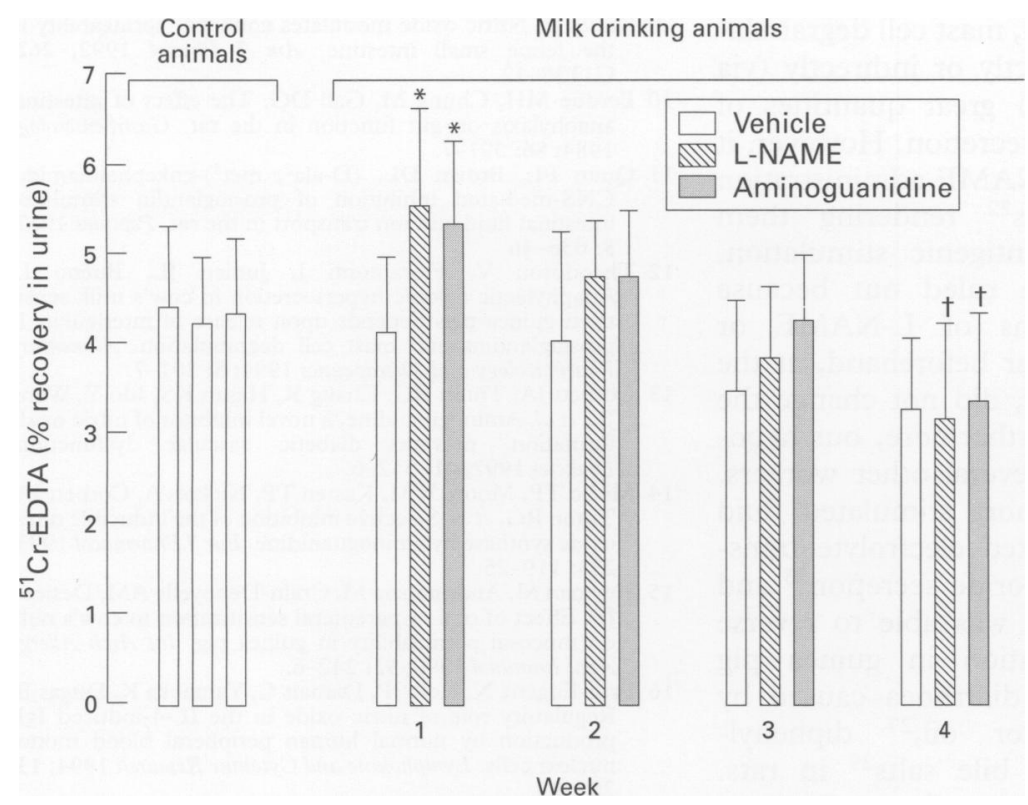

Figure 4: Mean values of intestinal permeability evaluated before and every week during the sensitisation period (milk drinking) in vehicle and NO synthase inhibitor treated guinea pigs. Note the significant rise of intestinal permeability after one week treatment in $N$-nitro-L-arginine methyl ester (L-NAME) or aminoguanidine treated animals and the progressive drop until the end of the milk diet. ${ }^{*}$ Significantly different from vehicle $(p<0.05)$. †Significantly different from values of the first week $(p<0.01)$.

We have shown that L-NAME and aminoguanidine are equally efficient at reducing the sensitisation rate. As L-NAME is a non-selective inhibitor of cNOS and iNOS and aminoguanidine is selective for iNOS, we suggest that NO production via iNOS is involved in the sensitisation process. iNOS has been reported to be induced after activation of different cells involved in immunological reactions by cytokines, ${ }^{2}$ and when expressed, this enzyme synthesises NO for a long period. This mode of induction fits well with our model in which antibody synthesis was cytokine dependent and the sensitisation process was time

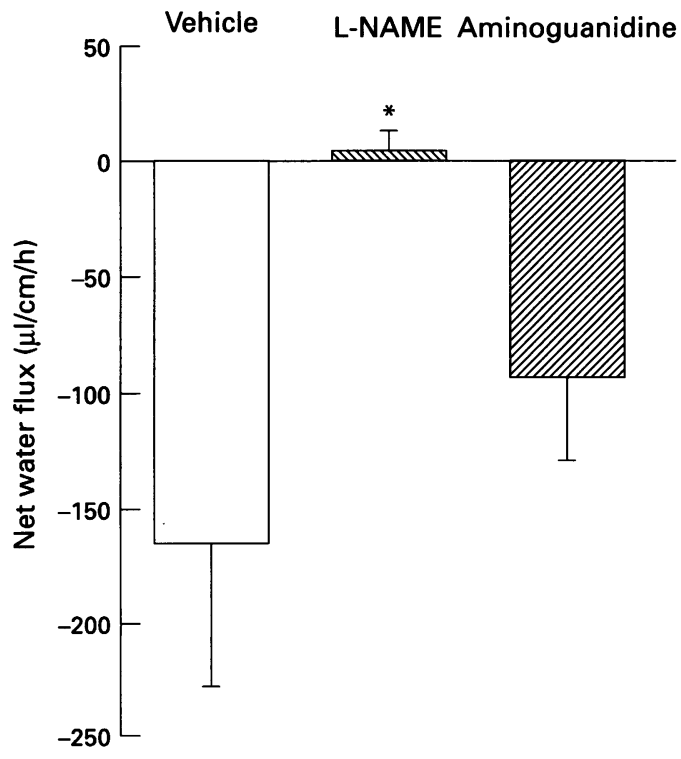

Figure 5: Comparative values of colonic water flux during antigen challenge in vehicle and NO synthase inhibitor treated guinea pigs. $N$-nitro-L-arginine methyl ester

(L-NAME) (10 mg/kg ip) and aminoguanidine $(2 \mathrm{mg} / \mathrm{kg}$ ip) were administered one hour before antigen infusion. Only L-NAME antagonised the hypersecretion induced by $\beta$ lactoglobulin infusion. * Significantly different from vehicle $(p<0 \cdot 01 ; n=6)$. related as animals were subjected to antigen for four weeks. Furthermore, this result agrees with in vitro studies showing that there is a striking correlation between NO release and IgE production and that the accumulation of NO becomes significant after about five days of stimulation, suggesting that this process requires the induction of iNOS. ${ }^{16}$

Intestinal permeability, which is involved in antigen penetration, was evaluated using ${ }^{51} \mathrm{Cr}$ EDTA as probe. This molecule is thought to permeate the intestinal epithelium by the paracellular route. However, ${ }^{51} \mathrm{Cr}$-EDTA passage has recently been shown to depend on water absorption in the villus tips according to their osmolality and on intestinal blood flow. ${ }^{18}$ Nevertheless, this test has been proved to be relevant in detecting intestinal inflammation by assessing changes in intestinal permeability in human as well as in experimental animal models. Inhibition of NOS has been found to increase intestinal permeability ${ }^{9}$ leading to a stronger antigen penetration and therefore a higher sensitisation rate. In our study, we observed a significant rise in intestinal permeability but only after the first week of NOS inhibitor treatment. This initial transient increase in intestinal permeability did not seem to be sufficient to increase the antigen uptake, since at the end of the sensitisation period the antibody titres were significantly lower in NOS inhibitor treated animals. Afterwards, intestinal permeability dropped progressively, reaching lower values at the end of sensitisation period. However, these values were quite similar in control and treated animals suggesting a possible defence reaction to antigen penetration by the mucosal epithelium independently of NOS inhibitor treatment. This finding provides additional support for a stimulatory role of NO on the immune response, particularly immunoglobulin production, whereas the possibility of higher antigen penetration by an NOS inhibition induced increase in permeability seems of less importance.

During the sensitisation period in animals treated with NOS inhibitors we observed a significant reduction in colonic hypersecretion upon antigen challenge. This result ,can be explained by the lower antibody titres found in these animals, suggesting that there may be a smaller number of activated immunocompetent cells and therefore a weaker release of inflammatory mediators. Indeed, the correlation between antibody titres and transport abnormalities is well established. ${ }^{10}$

The second part of our study showed that L-NAME, but not aminoguanidine, administered one hour before challenge reversed the hypersecretion triggered by $\beta$ lactoglobulin infusion. This leads us to think that NO synthesis via cNOS plays a prominent role in the antigen induced hypersecretion. NO is widely distributed throughout the intestine, including smooth muscle ${ }^{19}$ and inflammatory cells, neurons of myenteric plexus and epithelial cells. Moreover, NO is released from mast cells when activated ${ }^{20}$ and from vascular endothelial cells stimulated by inflammatory mediators ${ }^{21}$ produced by mast cell degranulation. We 
suggest that in our model, mast cell degranulation released either directly or indirectly (via inflammatory mediators) great quantities of NO which caused hypersecretion. However, it has been shown that L-NAME administration degranulates mast cells $^{22}$ rendering them insensitive to further antigenic stimulation. This possibility can be ruled out because challenge administrations of L-NAME or aminoguanidine one hour beforehand, at the doses used in this study, did not change the basal net water flux. Furthermore, our hypothesis is supported by several other workers. On one hand, NO donors stimulated fluid accumulation, 23 modulated electrolyte transport, ${ }^{24}$ and activated chloride secretion ${ }^{25}$ and on the other, L-NAME was able to reverse luminal fluid accumulation in guinea pig ileitis $^{26}$ and to prevent diarrhoea caused by administration of castor oil, ${ }^{27}$ diphenylmethane laxatives, ${ }^{28}$ or bile salts ${ }^{29}$ in rats. Moreover, and in support of our findings, recent work from our laboratory has shown that IL-1 is involved in the anaphylactic colonic hypersecretion induced by antigen challenge in the sensitised guinea pig $^{30}$ and that the IL-1 induced hypersecretion can be blocked by a NOS inhibitor. ${ }^{31}$ Alternatively, it has been reported that L-NAME displays some antimuscarinic action, ${ }^{32}$ which can explain the blockade of antigen induced hypersecretion since cholinergic neurons are involved in this secretory response. However, at the dose used, L-NAME exerts in vivo a stimulation of gut motility hardly compatible with an antagonism on muscarinic receptors.

We conclude that NO may function as a common or a final mediator, or both, in this model of hypersecretion.

We thank Mr P Marche and C Betoulières for their skilful technical assistance and J Laumailler for manuscript preparation. This work was presented in part at the Annual Meeting of the American Gastroenterological Association, San Diego, May 1995.

1 Palmer RMJ, Ashton DS, Moncada S. Vascular endothelial cells synthesize nitric oxide from L-arginine. Nature 1988; 333: 664-6.

2 Moncada S, Palmer RMJ, Higgs EA. Nitric oxide: physiology, pathophysiology and pharmacology. Pharmacol Rev 1991; 43: 109-42.

3 Brown JF, Tepperman BL, Hanson PJ, Whittle BJR, Moncada S. Differential distribution of nitric oxide synthase between cell fractions isolated from the rat gastric mucosa. Biochem Biophys Res Commun 1992; 184: 680-5.

4 Marletta MA, Yoon PJ, Iyengar R, Leaf CD, Wishnok JS. Macrophage oxidation of $L$-arginine to nitrite and nitrate: nitric oxide is an intermediate. Biochemistry 1988; 27: 8706-11.

5 Hibbs JBJr, Taintor RR, Vavrin S, Rachlin EM. Nitric oxide: a cytotoxic activated macrophage effector mole-
cule. Biochem Biophys Res Commun 1988; 157: 87-94.

6 Mc Call TB, Palmer RMJ, Moncada S. Induction of nitric oxide synthase in rat peritoneal neutrophils and its inhibition by dexamethasone. Eur $\mathcal{F}$ Immunol 1991; 21: 2523-7.

7 Miller MJS, Chotinaruemol S, Sadowska-Krowicka H, Kakkis JL, Munshi UK, Zhang XJ, et al. Nitric oxide: the Jekyll and Hyde of gut inflammation. 1993; Agents Actions Special Conference Issue: C180-2.

8 Coombs RRA, Devey ME, Anderson KJ. Refractoriness to anaphylactic shock after continuous feeding of cows' milk to guinea-pigs. Clin Exp Immunol 1978; 32: 263-71.
9 Kubes $P$. Nitric oxide modulates epithelial permeability in the feline small intestine. Am $\mathcal{F}$ Physiol 1992; 262: G1138-42.

10 Perdue MH, Chung M, Gall DG. The effect of intestinal anaphylaxis on gut function in the rat. Gastroenterology 1984; 86: 391-7.

11 Quito FL, Brown DL. (D-ala ${ }^{2}$, met ${ }^{5}$ )-enkephalinamide: CNS-mediated inhibition of prostaglandin stimulated intestinal fluid and ion transport in the rat. Peptides 1987; 8: $638-46$.

12 Theodorou V, Fioramonti J, Junien JL, Buéno L Anaphylactic colonic hypersecretion in cow's milk sensitized guinea-pigs depends upon release of interleukin 1 , prostaglandins and mast cell degranulation. Alimentary Pharmacology and Therapeutics 1994; 8: 301-7.

13 Corbett JA, Tilton RG, Chang K, Hasan KS, Ido Y, Wang $\mathrm{JL}$, et al. Aminoguanidine, a novel inhibitor of nitric oxide formation, prevents diabetic vascular dysfunction Diabetes 1992; 41: 552-6.

14 Misko TP, Moore WM, Kasten TP, Nickols A, Corbett JA, Tilton RG, et al. Selective inhibition of the inducible nitric oxide synthase by aminoguanidine. Eur $\mathcal{F}$ Pharmacol 1993; 233: 119-25.

15 Heyman M, Andriantsoa M, Crain-Denoyelle AM, Desjeux JF. Effect of oral or parenteral sensitization to cow's milk on mucosal permeability in guinea pig. Int Arch Allergy on mucosal permeability in guine

16 Paul-Eugène N, Kolb JP, Damais C, Yamaoka K, Dugas B. Regulatory role of nitric oxide in the IL-4-induced IgE production by normal human peripheral blood mononuclear cells. Lymphokine and Cytokine Research 1994; 13: 287-93.

17 Tan HP, Lebeck LK, Nehlsen-Cannarella SL. Regulatory role of cytokines in IgE-mediated allergy. $\mathcal{f}$ Leukoc Biol 1992; 52: 115-8.

18 Bijlsma PB, Peeters RA, Groot JA, Dekker PR, Taminiau JA, VanderMeer R. Differential in vivo and in vitro intestinal permeability to lactulose and mannitol in animals and humans: a hypothesis. Gastroenterology 1995; 108: and human.

19 Salter M, Knowles RG, Moncada S. Widespread tissue distribution, species distribution and changes in activity of $\mathrm{Ca}^{2+}$-dependent and $\mathrm{Ca}^{2+}$-independent nitric oxide synthases. FEBS Lett 1991; 291: 145-9.

20 Salvemini D, Masini E, Anggard E, Mannaioni PF, Vane J. Synthesis of a nitric oxide-like factor from L-arginine by rat serosal mast cells: stimulation of guanylate cyclase and inhibition of platelet aggregation. Biochem Biophys Res Commun 1990; 169: 596-601.

21 Sakuma I, Levi R. Vasomotor effects of leukotrienes C4 and D4 on cavian pulmonary artery and aorta: characterization and mechanism. In: Levi R, Krell RD, eds. Biology of the leukotrienes. New York: Ann New York Academy the leukotrienes. New

22 Kanvar S, Wallace $I L$, Befus D, Kubes P. Nitric oxide synthesis inhibition increases epithelial permeability via mast cells. Am F Physiol 1994; 266: G222-9.

23 Thomas DD, Knoop FC. The effect of calcium and prostaglandin inhibitors on the intestinal fluid response to heat-stable enterotoxin of Escherichia coli. $\mathcal{f}$ Infect Dis 1982; 145: 141-5.

24 MacNaughton WK. Nitric oxide-donating compounds stimulate electrolyte transport in the guinea pig intestine in vitro. $L$ ife Sciences 1993; 53: 585-93.

25 Wilson KT, Xie Y, Musch MW, Chang EB. Sodium nitroprusside stimulates anion secretion and inhibits sodium chloride absorption in rat colon. $¥$ Pharmacol Exper Ther 1993; 266: 224-30.

26 Miller MJS, Sadowska-Krowicka H, Chotinaruemol S, Kakkis JL, Clark DA. Amelioration of chronic ileitis by nitric oxide synthase inhibition. F Pharmacol Exper Ther 1993; 264: 11-6.

27 Mascolo N, Izzo AA, Barbato F, Capasso F. Inhibitors of nitric oxide synthetase prevent castor-oil-induced diarrhoea in the rat. Brf Pharmacol 1993; 108: 861-4.

28 Gaginella TS, Mascolo N, Izzo AA, Autore G, Capasso F. Nitric oxide as a mediator of bisacodyl and phenolphtalein laxative action: induction of nitric oxide synthase. f Pharmacol Exper Ther 1994; 270: 1239-45.

29 Mascolo N, Gaginella TS, Izzo AA, Dicarlo G, Capasso F. Nitric oxide involvement in sodium choleate induced fluid secretion and diarrhea in rats. Eur $f$ Pharmacol 1994; 264: 21-6.

30 Theodorou V, Fioramonti J, Buéno L. Recombinant interleukin-1 receptor antagonist protein prevents sensitization and intestinal anaphylaxis in guinea pigs. Life Sciences 1993; 53: 733-8.

31 Eutamène $H$, Thedorou $V$, Fioramonti $J$, Buéno $L$. Implication of both $\mathrm{NK}_{1}$ and $\mathrm{NK}_{2}$ receptors in rat colonic hypersecretion induced by interleukin $1 \beta$ : role of nitric oxide. Gastroenterology 1995; 109: 483-9.

32 Buxton ILO, Cheek DJ, Eckman D, Westfall DP, Sanders $\mathrm{KM}$, Keef $\mathrm{KD}$. $\mathrm{N}^{\mathrm{G}}$ Nitro L-arginine methyl ester and other alkyl esters of arginine are muscarinic receptor antagonists. Circ Res 1993; 72: 387-95. 